* Corresponding author Phone: +421556023587 E-mail address: stefan.babjak@tuke.sk (Štefan Babjak, Ing. PhD.)

Article information Article history: AMS-Volume15-No.4-00127-11 Received 28 March 201

Accepted 24 May 2011

\section{Product Innovations and Agile Manufacturing}

\author{
Milan Kováč, Štefan Babjak*, Michal Dúbravčik, Andrea Lešková
}

Department of Technologies and Materials, Faculty of Mechanical Engineering, Mäsiarska 74, 04201 Košice, Slovak Republic

\section{BIOGRAPHICAL NOTES}

Milan Kováč, prof. Ing. DrSc. Director of the Institute of Technology and Management and head of the Section of automotive production at the Department of technology and materials, works at the Faculty of Mechanical engineering, Technical university of Košice since 1969. He was the head manager of number of state grants and commercial innovation projects, and also four international research projects. Milan Kováč is author and co-author of monographs, books and publications focused on planning and projection of production processes and systems, automation, robotics, reengineering and innovations, Kaizen and lean production, and development trends in the field of automotive industry. He is also winner of several domestic science awards. Nowadays, his primarily field of interest in research includes the questions of innovation strategies, systems of innovation creation and preparation, and building the support infrastructure for innovations.

Štefan Babjak, Ing. PhD. graduated at the Technical university of Košice in 2003 and also obtained the PhD. degree in 2008 there, both in the field of Mechanical engineering technologies and materials with specialization on the innovations of products and production systems. Nowadays, he is a researcher at the Section of automotive production at the Department of technology and materials and his field of interest is focused on methods and techniques leading to various improvements of innovation preparation process primarily oriented on the automotive industry, including Rapid prototyping, reverse and simultaneous engineering, wikinomics, crowdsourcing, open and user innovations, innovation process support via creative e-communities, and Kaizen, agile, and lean approaches in product design. Štefan Babjak is author of one monograph, co-author of three books, and author of number of science papers.

Michal Dúbravčík, Ing. PhD. graduated at the Technical university of Košice in 2004 and also obtained the PhD. degree in 2008 there, both in the field of Mechanical engineering technologies and materials with specialization on the automotive production. Nowadays, he works as an assistant at the Section of automotive production at the Department of technology and materials and his field of interest is focused on methods and techniques leading to various improvements of innovation preparation process primarily oriented on the automotive industry, including Rapid prototyping, reverse and simultaneous engineering, 3D scanning, composite materials processing, open and user innovations, and Product design. Michal Dúbravčík is co-author of two books and author of number of publications.

Andrea Lešková, Ing. PhD. graduated at the Technical university of Košice in 1999 and also obtained the PhD. degree in 2005 there, both in the field of Mechanical engineering technologies and materials with specialization on the innovations of products and production systems. She currently works as an assistant at the Section of automotive production at the Department of technology and materials, and her research activi- 
ties are focused on the methods and techniques for various improvements of innovation process, primarily oriented at the automotive industry, including Project management, Kaizen and lean approaches in product and process design, and designing of workstations. She is co-author of two books, four textbooks, and author of number of science papers.

\section{KEY WORDS}

Product Design, Agile Manufacturing, Knowledgeintensive Services, Innovation Techniques Integration, Innovation Management

\section{ABSTRACT}

The automotive sector is facing advanced challenges arising from global changes in the technical, economic and social environment. Trend, referred to as the "agile manufacturing" represents the ability to survive and prosper in a competitive environment of continuous and unpredictable changes. It means to respond quickly and effectively to changing markets, produce goods and services according to customer needs via maintain the continuous product innovation, manageable number of product variants, fulfilling the unpredictable requirements of customers, shortening product life cycle and respond to significant fluctuations in sales. Submitted article describes the philosophy of solving the task "Product design for high-tech production systems and risk management of innovative projects" within the frame of the project "Center for research of control of technical, environmental and human risks for permanent development of production and products in mechanical engineering" and provides selected results from analytical and experimental research and building of the laboratory.

\section{Introduction}

In the present and medium term perspective in the future, the mechanical engineering and other industrial branches are facing advanced challenges arising from global changes in the technical, economic and social environment. They are influenced by the previous financial crisis, followed by the debt crisis (pressure to reduce costs, entering the new markets, innovation and so on).

There is growing the need for products with higher added value, based on new knowledge im- plemented from research. It seems to be the only way to compete with the mass production of lowcost countries and changes in the field of technology. Lots of renowned analyses worldwide indicate that currently there is a technological turning point, which is e.g. in the automotive industry the biggest over the past 50 years. To adapt quickly to changing market conditions is in this case "sine qua non". For companies, this means maintain the continuous product innovation, manageable number of product variants, fulfilling the unpredictable requirements of customers, shortening product life cycle and respond to significant fluctuations in sales. However, to prepare the production system for possible changes is no longer economically viable. The main principle of the adaptability of production systems is the ability to allow rapid adaptation of the organization and technology at low investment costs. This trend is referred to as the "agile manufacturing" and it represents the ability to survive and prosper in a competitive environment of continuous and unpredictable changes. It means to respond quickly and effectively to changing markets, produce goods and services according to customer needs. Agile manufacturing requires adequate research, alliance based on competencies, organizational structures capable of managing change and uncertainty through innovation, and utilizing the potential of people, information and knowledge.

Following article describes the philosophy of solving the task "Product design for high-tech production systems and risk management of innovative projects", which is part of the "Excellence center" project at the Faculty of Mechanical Engineering, Technical University of Kosice. It also provides selected results from analytical and experimental research and building of the laboratory.

\section{Project characteristics}

The project activity is aimed at the new knowledge and methodologies of implementation in practice for innovation of designing and implementation of production systems, high-tech products and the development of knowledge-intensive services to eliminate the risk of innovative projects. The plan of solution was formulated by type structure as follows:

- Analysis of the background and creation of a methodological approach 
- Specification of activities

- Analytical and experimental research

- Synthesis of the knowledge base

- Development of the implementation procedures for the practice

- Completion of the laboratory base for the providing of knowledge-intensive services

- Testing the pilot applications, evaluation of the results and optimizing.

Detailed structure of the project activities describes table 1.

Table 1: Detailed structure of the project activities.

\begin{tabular}{|c|}
\hline PRO \\
\hline $\begin{array}{l}\text { Integrated innovation cycle } \\
\text { "creativity - design - engineering - prototyping - testing } \\
\text { - manufacturing design - agile manufacturing" }\end{array}$ \\
\hline $\begin{array}{l}\text { Building the knowledge base } \\
\text { Analyses, monitoring, surveys of needs, trends, } \\
\text { innovations and best practices }\end{array}$ \\
\hline $\begin{array}{l}\text { Development and testing of innovation processes for } \\
\text { product innovation and design of manufacturing systems } \\
\text { Development of specialized practices in product deve- } \\
\text { lopment and production systems, using new analytical } \\
\text { and experimental methods: } \\
\text { Elimination of contradictions between product } \\
\text { design and manufacturability using the TRIZ method } \\
\text { DFM/A - oriented procedures of product develop- } \\
\text { ment } \\
\text { Development of products focused on productivity, } \\
\text { advanced level of innovation, flexibility, re-configurabi- } \\
\text { lity, lean and environmental design } \\
\text { Variant-based generation of product design for agile } \\
\text { manufacturing systems } \\
\text { Fabrication of samples and prototypes based on new } \\
\text { processes and technologies } \\
\text { Development of procedures for knowledge-intensive } \\
\text { services }\end{array}$ \\
\hline $\begin{array}{l}\text { Building the laboratory facility } \\
\text { Research, development, testing and providing of } \\
\text { knowledge-intensive services in the field of innovation } \\
\text { of high-tech products and automotive components: } \\
\text { - Process the analyses of needs and requirements of } \\
\text { selected target groups on service product development } \\
\text { and design of production systems } \\
\text { - Develop the innovative methodologies and procedu- } \\
\text { res for integrating IIT and IMTs as part of KIBS } \\
\text {-Perform the testing of developed methodologies } \\
\text { based on pilot projects }\end{array}$ \\
\hline $\begin{array}{l}\text { Implementation of innovative methods of product design } \\
\text { within the network of partners (manufacturers and re- } \\
\text { search and development centers) }\end{array}$ \\
\hline
\end{tabular}

\section{Principles of agile manufacturing as the methodological basis of the solution \\ 3.1 Characteristics of agile manufacturing}

In the 90's appeared the first attempts to integrate a large number of general innovative changes in leader industrial branches into a new concept called "future factory, manufacturing for the 21 st century". There were formulated first concepts of agile manufacturing [1].

Already in 2000, some car manufacturers started to apply the principles of agile manufacturing. For example, Volkswagen's annual report 2000 states: "Characteristic signs of our company in the future will be: customer orientation, focusing on the processes of adding value and flexibility in personnel and technical systems. We emphasize that every working station has its own customer, every employee is a local supplier and at all levels of production we apply the principle of competitiveness and innovation."

In 1996, there was published a study named Technologies Enabling Agile Manufacturing (TEAM). As the main tools of agile technology were identified these: product design and simultaneous engineering, virtual manufacturing, production planning and control, intelligent processes and enterprise integration. As the support systems are defined technology suppliers, industrial and research laboratories and national support agencies [2]. Refined definition of the concept of agile manufacturing is

Agile manufacturing can be defined as the ability to survive and to prosper in a competitive environment of continuous and unpredictable changes. It means to respond quickly and effectively to changing markets, produce goods and services according to customer needs. Agile manufacturing is not about the continuous improvement. Agile manufacturing is a term that is used to represent the ability of a manufacturer of products and services to respond effectively in conditions of incessant changes. These changes can occur in markets, technologies, business relationships and in all aspects of business [3].

The starting point of agility is flexibility. Agile manufacturing is an operational strategy designed to achieve rapidity and flexibility of a variable range of products with the minimum times for setup and production interruptions. Products of the agile manufacturing compete with conventional products and they provide customer with configurable opportunities and product specialization. Other im- 
portant features of flexible production systems in relation to agility are:

- Identification of the individual work units.

- Quick readjustment of work process.

- Quick readjustment of the physical setting of the workplace (plant, forms, tools).

Agile production is different from the lean in the sense that lean production is oriented on the repetitive manufacturing environment with focus on high-volume and low mix, since the agile production is applicable to low-volume and high mix. It is suited to an environment where configurable or specialized products offer a competitive advantage [4]. Characteristic features of agile manufacturing are:

- Rapid development of new products. Modular structure of products and assembly procedures, on-demand configuration of products, configurable components, low volumes and high range of products. Short / quick order processing.

- Short market delivery time. Short / quick order processing, production according to orders, low volumes and high range of products, fast delivery from subcontractors.

- Short times of cycles. Highly flexible and responsive processes, highly flexible machinery and equipment, application of principles of group technology, using advanced CAM /CAP, rapid readjustment, cell grouping of machinery, equipment, tools and people, lean manufacturing space.

\section{- Versatile and motivated employees.}

Table 2: Structural features of agile manufacturing

\begin{tabular}{|c|c|}
\hline \multicolumn{1}{|c|}{ STRATEGIES } & TECHNOLOGY \\
\hline Re-configurability & Fast hardware \\
\hline Virtual enterprise & $\begin{array}{c}\text { Flexible machinery, equip- } \\
\text { ment and jigs }\end{array}$ \\
\hline Strategic alliances & Modular working stations \\
\hline Reengineering & Real-time control \\
\hline $\begin{array}{c}\text { Integration of the supply } \\
\text { chain }\end{array}$ & Information technology \\
\hline Advanced logistics & CAD / CAE, CAPP, CAM \\
\hline Heterogeneous compu- & Multimedia \\
\hline ting systems & Graphic simulation \\
\hline Simultaneous engineering & PEOPLE \\
\hline SYSTEMS & Flexible workforce \\
\hline MRP II, Internet & Knowledge level of staff \\
\hline E-commerce
\end{tabular}

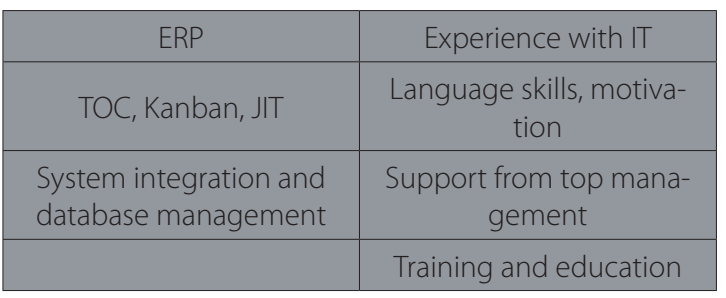

\section{Selection of the innovation model for the solution}

An important part of the preparatory phase of the project is the analysis of innovation models and selection of the preferred model. Models of innovation inherently respond to changes in the innovation environment, so there are many different models. Basically, there can be distinguished 2 main groups and 5 basic generations of models, as follows [3]:

\section{Traditional linear models of innovation:}

- Push model: Science initiates innovation (new knowledge - innovative design - production - customer)

- Pull model: Demands of potential customers - innovation comes from the unmet needs of customers (customers - innovative design - production)

Interactive models: Combination of push of science and pull of customer demands through the feedback loop. Research, development and marketing are in balance.

- Coupling model: interactions between the different elements and feedback between them.

- Parallel model: integration between the companies, linking with key suppliers and active customers, emphasis on bindings and alliances, system integration, large networks, flexible and tailored response to continuous innovation.

- Network model: system integration, wide networks, flexible and tailored reactions of radical innovations.

The driving forces behind the network innovations are growing difficulties to maintain competitiveness in the field of technology and product development. Product life cycles are becoming shorter due to rapid technological developments and change of customer preferences. At the same time, the cost of $R \& D$ and technical requirements for new products are increasing, the availability of talented workers is decreasing and the degree of specialization increases. These three forces increase the pressure on the efficiency of research and development.

The transformation from traditional, closed innovation to modern, open and performed within 
the network, is not without problems. Trend is to work also with partners with not clearly and poorly structured problems related to innovation, comprehensive thinking on innovation with a strong focus on future developments and the possible needs of potential users. The challenging tasks of design of innovation processes in the network are:

- Knowledge of integration across the organizations

- Format of partnership for innovation in the network

- Identification of strategic partners

- Balancing the goals and future vision for innovation in the network

- Team structures for innovation in the network

- Skills and practices for innovation networks

- Model for network innovation

\section{Experimental project activities \\ 5.1 Digitizing and Reverse Engineering}

An important aspect of innovation agility is prototyping. Here becomes its importance, among the other innovative activities, the computerized processing of data interception of external shape of the model - 3D digitization. The issue of digitization acquired its importance especially after the introduction of the rapid prototyping (RP) technologies and related utilization of physical models. The project team is testing 3D digitizing within the processes of product design, using two 3D scanning devices. The first device is contact 3D digitizer MicroScribe $\mathrm{G} 2$, the second one is the measuring arm FARO with laser scanning head. There are applied several methods of scanning for data processing. The most common method is the point method, which includes the capturing of a large number of points in space (point cloud) and they are then processed into the 3D model. The tests were performed on various car components: rear mirror, car model, powertrain elements, car seat, etc. The driven experiments in the field of digitization include:

- Comparison of speed and accuracy of various scanning techniques.

- Reverse engineering of automotive components applicable in the product design

- Measurements of accuracy

- Comparisons of methods of applying product design methodology utilizing the digitization

\subsection{Samples fabrication}

State-of-the-art product design in the automotive production requires enhanced utilization of prototypes, which means that the samples fabrication is one of the crucial parts of the innovation process. Within the frame of the project first phase is the main focus on the using of composite materials. There are a number of available technologies units which include among others:

- Hand-layering technology

- Vacuum molding

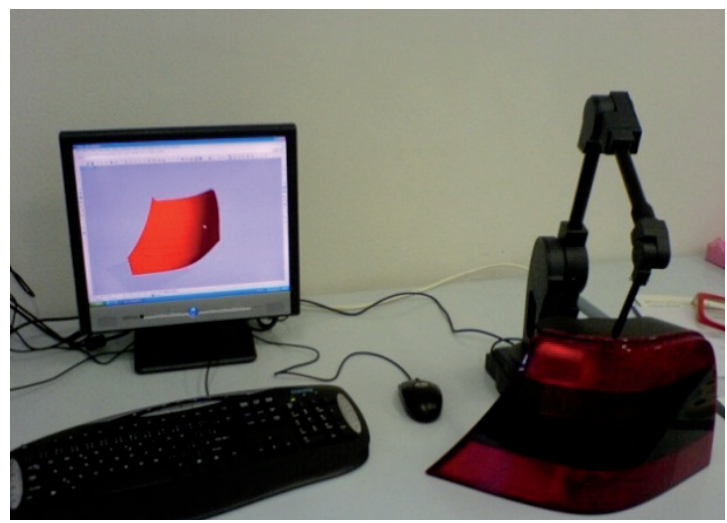

Fig. 1: Mechanic contact 3D scanner Microscribe G2.

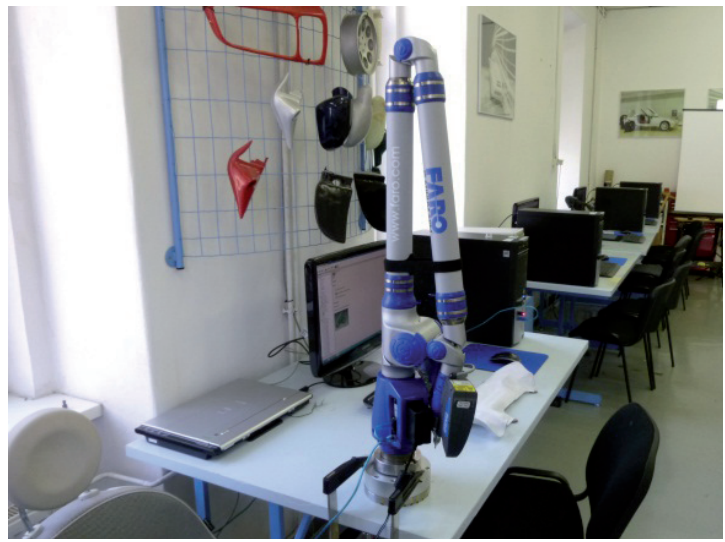

Fig. 2: Measuring arm FARO with laser scanning head

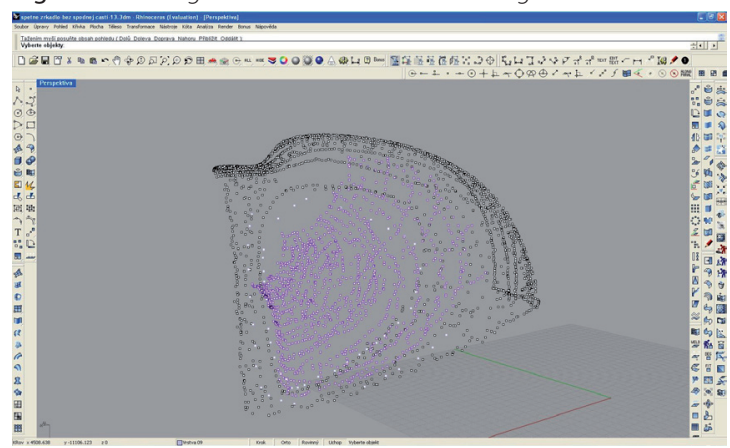

Fig. 3: Scanned point cloud of the rear mirror. 


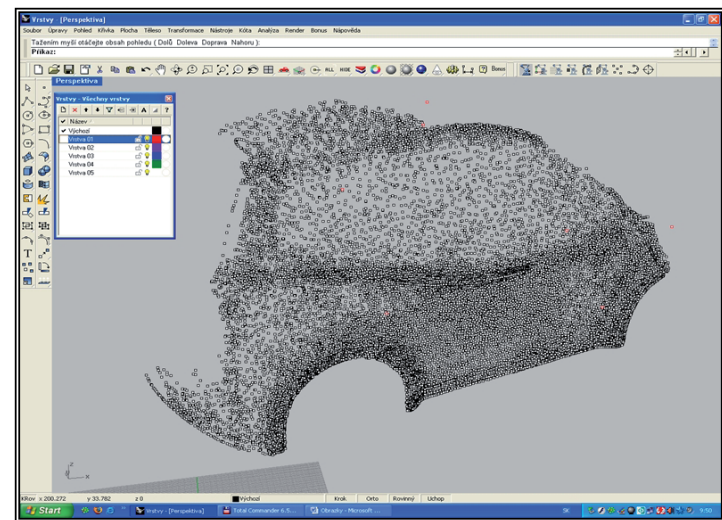

Fig. 4: Scanned point cloud of the car model.

These two methods form the basis of samples fabrication for experiments. Hand-laying technology is technically less demanding, but the resulting samples have a relatively large mass. In contrast, vacuum molding technology is technically more difficult, but the samples produced by using this technology have excellent weight and strength properties. The basic material used in the production of samples is carbon fiber processed into the carbon composite. This material has the greatest potential for the automotive industry, so focusing on this type of composite material is the priority. Reducing the weight of components manufactured using the composite materials based on carbon fibers is closely associated with the need to monitor their mechanical properties. Weight loss in the real component may cause the unfavorable influence the mechanical properties of the resulting components.

The biggest impact on the resulting change in mechanical properties of products produced by such methods has been proven the corresponding processing technology of carbon in final form, as well as the way of layering of the composite fabric. There has been ran a number of tests, where 10 test samples were made in each, using different technologies and different way to fold the fabric. Samples were made from carbon fiber according to the prescribed shape of the samples for a particular type of test. There were performed among the other tests (Fig. 7):

- Static tensile test - on a tensile machine TIRA - test 2300

- Deep drawing Erichsen test - test was performed on Hydraulic Machines RM - 501

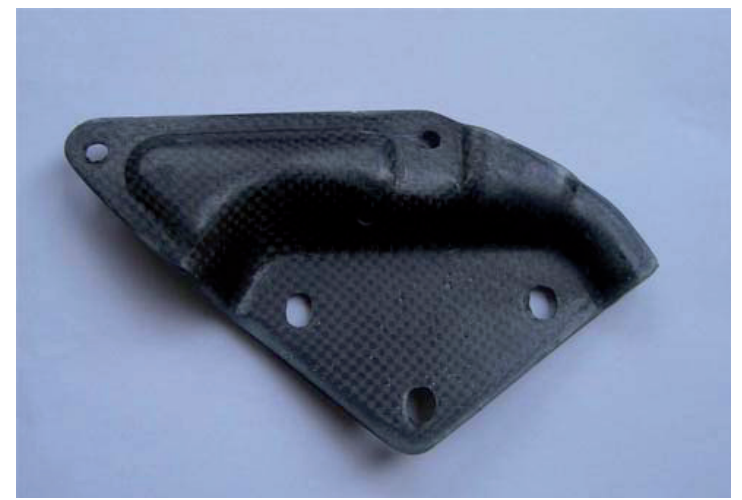

Fig. 5: Part of the bonnet hinge made of carbon composite.

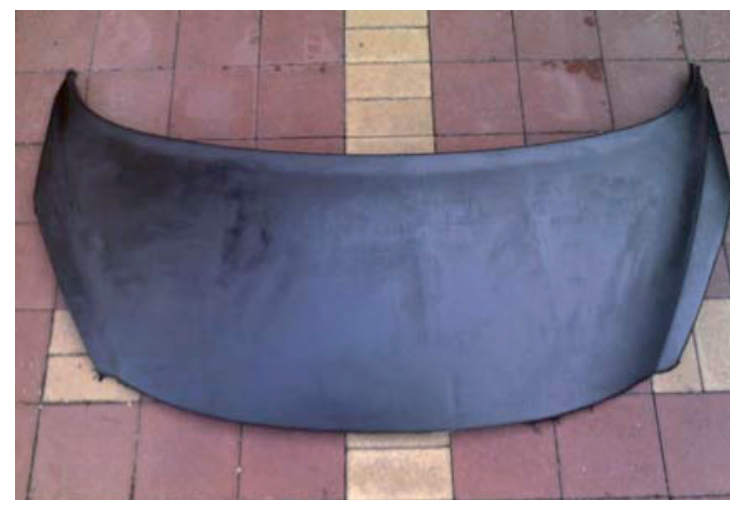

Fig. 6: Hood of the Peugeot 207 made of the carbon composite.
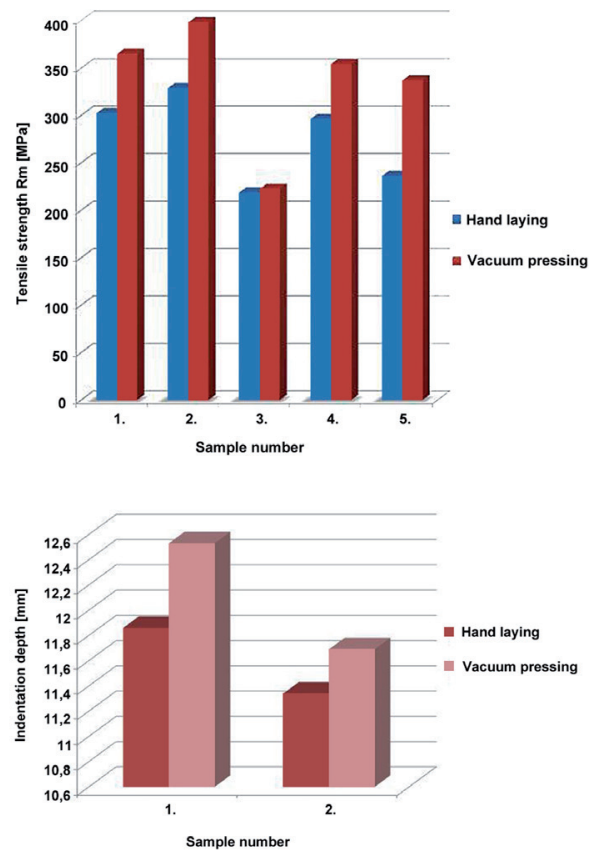

Fig. 7: Sample testing results of tensile and deep drawing Erichsen test. 


\section{Building of the laboratory}

Important part of the Center of excellence project is the building and development of the Product design laboratory. The main equipment of the laboratory are 4 computer stations for product design and precision measuring station equipped with the FARO PlatinumArm and laser scanning head. Brief description of the specific workstations and equipment in the laboratory:

Station of digitizing and reverse engineering: The scanning and measuring system consists of two basic parts - the 7-axes measuring arm FARO PlatinumArm with scanning device - laser scanning head. The system works with operating software Polyworks, which can be used in the field of reverse engineering, as well as in the quality control for accurate measuring. Selected features:

- Device has seven degrees of freedom that allow perfect movement and simple and accurate scanning of objects

- Built-in balancing device makes it possible to perform scanning with one hand

- Small footprint, particularly in the fixing

- Built-in sensors compensate in real-time thermal expansion of arm material

- The system has built-in battery that allows up to eight hours of work without a power supply

- Technical data: measuring accuracy of the arm $\pm 0.025 \mathrm{~mm}$, laser head measurement frequency 13,440 points per second, weight: 265 g, scanning distance: $101.6 \mathrm{~mm}$ to $165.1 \mathrm{~mm}$

Computer stations for product design. The laboratory is equipped with four workstations with software for product design: Adobe Design Premium,Autodesk Maya, Rhinoceros, PolyWorks. Among the software systems used previously were CATIA, Pro / Engineer, AutoCAD. Software packages are fully usable for the needs of product design and creation of 3D models. Most renowned of them is Maya, which offers comprehensive creative environment with a comprehensive tool for 3D animation, modeling, simulations, visual effects, rendering, Matchmoving (tracking) and compositional work. Use of this software is in particular of the design of automotive components, such as proposals to design car seats. The resulting design can be further processed in CAD programs such as CATIA.

\section{Knowledge-intensive services}

Activities of knowledge-intensive service (KIS) aimed at innovation and overall development of higher added value consists in collecting, concentrating and diffusion of expert knowledge. KIS providers develop the product solutions via application of new knowledge and support of IT tools, adaptation of existing knowledge from different sectors of the economy, create unique solutions and integrate the outputs of innovation intelligence into the business processes. Knowledge-intensive services contribute significantly to the improvement and acceleration of product, process and organizational innovation processes and transfer of best practices. Functional system of transfer of innovation in knowledge-based services is characterized by mutual interaction of the actors of commercialized research and development (universities, research organizations, technology transfer agencies, consultants, educational institutions, SMEs ...), who conduct screening of new knowledge and systematically seek information that could be commercially evaluated and thereby stimulate the innovation activities in enterprises. Knowledge services supporting the innovation performance of enterprises combine multidisciplinary expertise. It leads to mutual

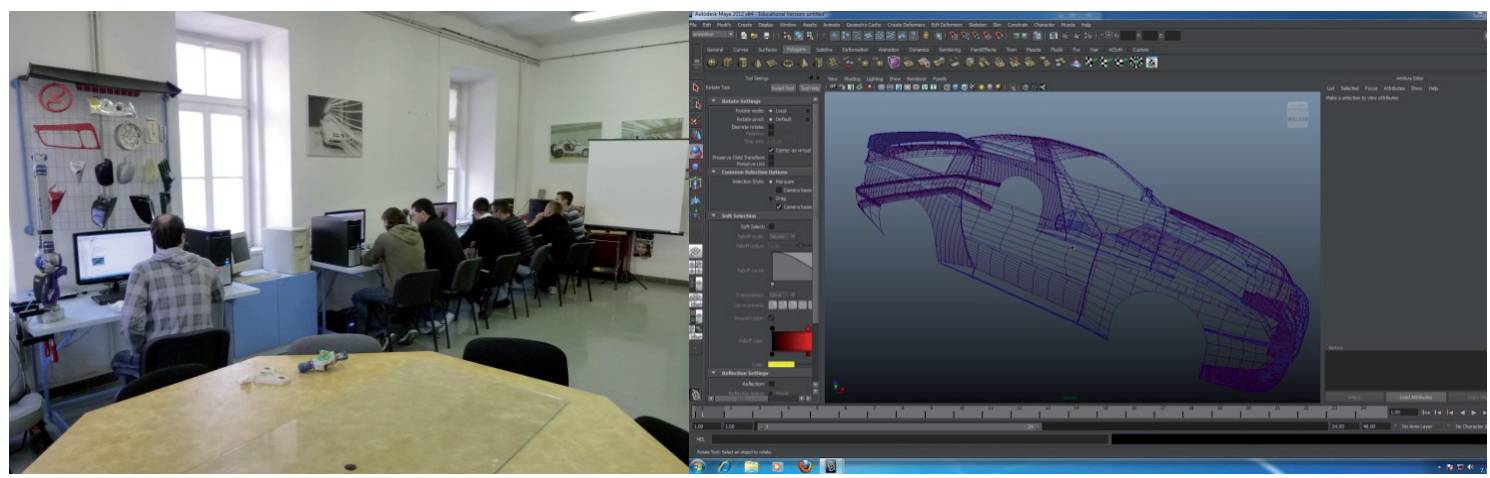

Fig. 8: Product design laboratory and interface of the Maya software. 
combination of knowledge bases, mutual learning process, and creation of new knowledge, up to the merge and implementation of experience, which was for the enterprises previously not available, or the enterprises were not available to effectively use it without the necessary consulting support. The providers of KIS up-and-coming open up the new strategic possibilities for innovative business development. It is realized through the accumulation of new scientific information from other branches or through the transfer of specific knowledge between sectors towards the comprehensive sophisticated product and technological innovations. The overview of important services related to product design and development illustrates the Fig. 9.

\section{Conclusion}

The activity 3.3: Product design for high-tech production systems and risk management of innovative projects as a part of project implementation: Center for research of control of technical, environmental and human risks for permanent development of production and products in mechanical engineering is intended to contribute to the development of solutions for innovative creation of engineering products, with primary orientation on automotive components, development of methodologies for implementing the innovative methods of automotive components design within the network of partners from suppliers and creating the methodology of preparation of platforms for cooperation. An important benefit of the project is the completion of the Laboratory of automotive production at Faculty of Mechanical Engineering TU of Kosice, oriented on the integrated innovation cycle "creativity - design - engineering - prototyping - testing - application procedures". Main goal of the project activity is to create an integrated system of design preparation of automotive components, using the approaches of Rapid prototyping and reverse engineering, utilizing the support of the integrated system of knowledge-intensive services. The knowledge basis, tools, and methodologies that are currently under development, should support the preparation, management and implementation of innovation in the sector of automotive suppliers, especially in the segment of small and medium enterprises to help upgrade their current state to higher levels with higher added value, as seen from the innovation perspective, whether through the support of agility or lean approach implementation into the development processes.

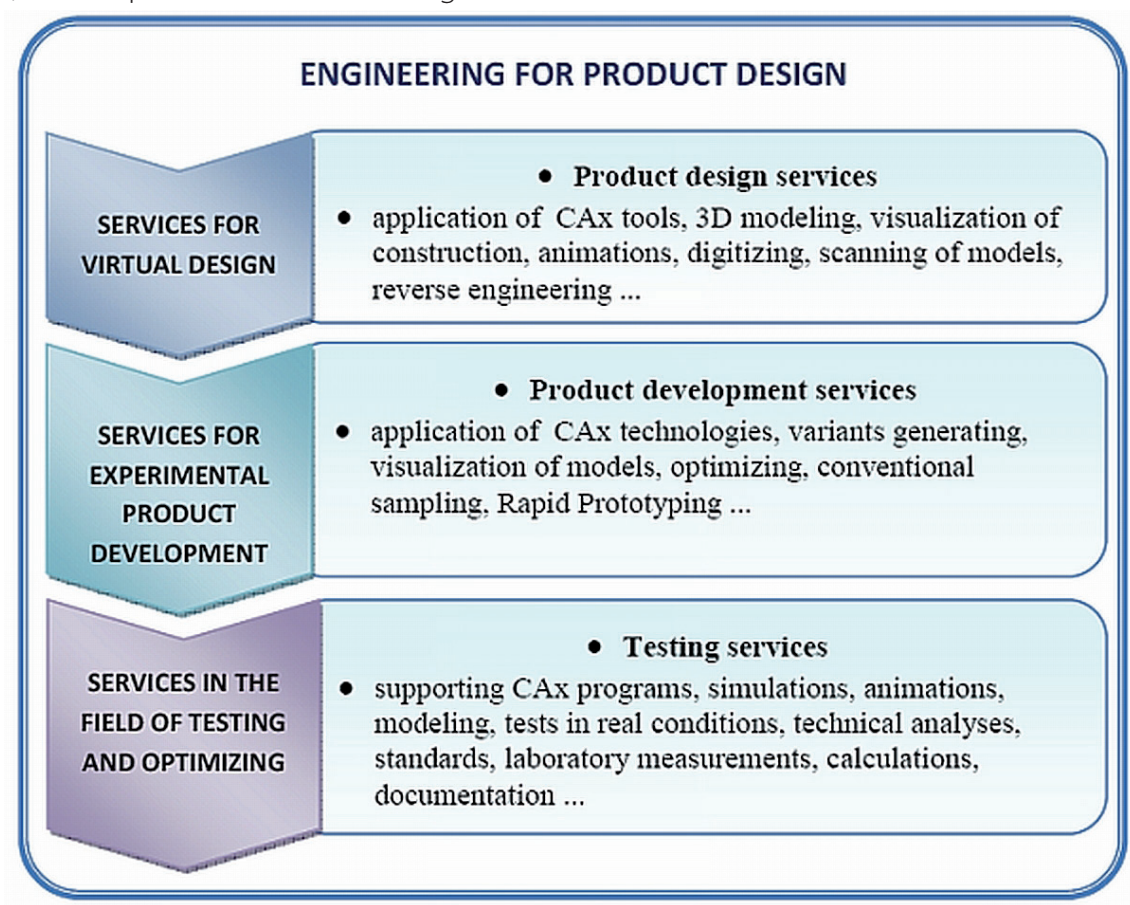

Fig. 9: Selected engineering-based knowledge services to support innovation. 


\section{Acknowledge}

This contribution is the result of the project implementation: Center for research of control of technical, environmental and human risks for permanent development of production and products in mechanical engineering (ITMS: 26220120060) supported by the Research \& Development Operational Programme funded by the ERDF.

\section{References}

[1] Gunasekaran, A.: Agile manufacturing: A framework for research and development Int. J. Production Economics 62 (1999), pp. 87-105.

[2] Hugos, M. IT Infrastructure for the Agile Enterprise: Grid, SOA, and Virtualization Center for Systems Innovation www.MichaelHugos.com

[3] Zhang, J., Gu, J., Li, P., Duan, Z. Object-oriented modeling of control system for agile manufacturing cells Int. J. Production Economics 62 (1999), pp. 145-153

[4] Sanchez, L. M., Nagi, R. : A review of agile manufacturing systems, Int. J. Prod. Res., 2001, vol. 39, no. 16, ISSN 35613600

[5] Groover, M.P.: CLASSIFICATION OF MANUFACTURING SYSTEMS, Lehigh University. Online: http://online.lesn.lehigh. edu/Level of Flexibilitycourses/mse438/mse438-5bL.htm

[6] Gray, W. H., Neal,R. E., Cobb, C. K. A Review of the Technologies Enabling Agile Manufacturing Program, 1996 Oak Ridge National Laboratory

[7] Tidd, J.-Bessant, J.-Pavit, K. :Managing Innovation: Integrating Technological, Market and Organizational Change, Amazon, 2005

[8] Innvation models patterns. Online: www.uio.no/.../2\%20 meeting\%20-\%20Innovation,\%20models,\%20patterns.ppt

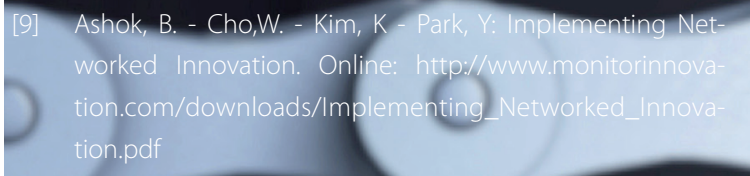

[10] Hämäläinen, T. J. - Schienstock, G.: Innovation Networks and Network Policies, 2000. Online: http://www.oecd.org/ dataoecd/35/8/2100869.pdf

[11] Gözüm. M. S. - Lütfi Kırdar L.: Networked Innovation:Generating \& Exploiting Ideas in the 21 stCentury Organization, Proc. Congres Networked innovation, November 28, 2007

[12] Kováč, M.: Fenomén inovácií. In. Podpra inovácií. Multiprint, Košice 2010

[13] Ebersberger, B.: The Use and Appreciation of Knowledge Intensive Service Activities in Traditional Industries. VTT Technology Studies, Finland 2004, ISBN 951-38-6560-6.

[14] Kuusisto, J., Meyer, M.: Insights into services and innovation in the knowledge-intensive economy. Tekes - the National 